\title{
Exploring Factors in Contributing Student Progress in the Open University
}

\author{
Muhammad Husni Arifin
}

\begin{abstract}
The Open Universities nowadays have been growing up with the high number of students. At the same time, they also facea high number of non re-enrolment and in turn have affected the retention rate. This study was aimed to explore factors contributing to student progress in the Indonesia Open University by employing mixed methods study. In this study, student progress refers to continuation of learning by re-enrolling within four consecutive semesters. A mixed methods research with the design of sequential explanatory study was opted by obtaining the quantitative findings from surveying 127 students and then was followed by multiple case study from four purposefully selected respondents. In the quantitative phase, 12 predictor variables were found to have important contributions to the predictive model of student progress. Meanwhile, in the qualitative phase, three major themes emerged from the multiple case study analysis: 1) self-motivation; 2) quality of institutional support; 3) interaction; and 4) supporting environment. The quantitative and qualitative findings are discussed with reference to previous research.
\end{abstract}

Index Terms-Student progress, Open University, distance education.

\section{INTRODUCTION}

There are much evidence that retention in distance education programmes is lower than in conventional or face to face programmes[1], [2]. Carr [3] shed light that retention in distance education programmes has been often $10-20$ percentage points lower than in conventional programmes and less than $50 \%$ of distance education students finish their courses. Furthermore, Rovai [4] also portrayed that adult students in campus programmehave lower retention rates than conventional aged students.

The low retention rate in distance education contexts has attracted researchers to investigate the factors influencing student retention in different contexts and theoretical frameworks. In general, there were 2 influential models used to explain the persistence of adult learners [4]: 1) psychological model of persistence; and 2) a model of institution-student "fit". The psychological model asserts that motivation and volition have important contribution in explaining persistence. At a certain condition, motivation can be used to depict why student motivated to enroll in the programme but it is not sufficient for explaining the fluctuation of motivation when obstacles and distractions occur during the learning process. At this point, persistence can be explained from volitional process which has functions

Manuscript received July 1, 2014; revised September 11, 2014.

Muhammad Husni Arifin is with University of Southampton, the United Kingdom (e-mail: mha2e11@soton.ac.uk). to maintain focus and effort toward goals despite potential distractions [5]. Meanwhile, a model of institution-student "fit" is a more recent model and explains the persistence by looking at the student, institutional, and environmental variables. Several influential models in this approach are Tinto's Model of Departure [6], [7], Bean and Metzner's Model [8], and Kember's Model of Student Progress [9]-[11].

The empirical studies on student persistence in distance education conducted in the past 10 years (2000-2010) have validated the function of both models. The findings of those studies reported that student persistence mostly can be explained from three significant factors: student factors, course/programme factors, and environmental factors. Student factors consisted of several sub-factors, such as academic background; prior educations; relevant skills, and psychological attributes, for instance, motivation, locus of control, self-efficacy, and satisfaction. Course/programme factors encompassed course design, institutional supports, and students' interactions. Meanwhile, environmental factors comprised work commitments and supportive study environments including supports from family, friends, or collegues [12].

However, most of those empirical studies were conducted in online learning programmes in dual mode institutions, an institution that adds distance education to its previously established campus and class-based teaching. These dual mode institutions have different characteristics with Open Universities as single-mode institutions, distance learning universities that all faculty and staff of the institution are exclusively devoted to distance education. The Open Universities typically aim to deliver education to students who are not physically "on site" and typically employ open entry admission [12], [13].

The existence of the Open University worldwide as a single-mode institution has made higher education being more accessible than before, particularly for people whose live in a limited economy and in isolated rural areas [14]. There are the huge growing number of students who enrolled in the Open Universities and most of them are classified as mega universities with at least 100.000 students [15], [16]. Moreover, the largest number of distance learners in the world was located in the Asian context and was served by 10 mega universities and around 100 distance education institutions [17].

This study investigates factors influencing student progress in the Indonesia Open University and the extend to which the three identified factors (internal, institutional, and external factors) influence student progress. Student progress in this study refers to the behavior of continuing learning and progressive re-enrolment despite the presence of obstacles 
within four consecutive semesters. In the contrary, a student who does not enroll and take courses within four consecutive semesters is classified as an inactive student. The purpose of this sequential explanatory mixed methods study is to explain the predictors of student progress in the Indonesia Open University and the extent to which the identified predictors influence student progress by employing a quantitative method with survey design and then following-up with obtaining qualitative data from semi-structured interviews. In the first phase, this study determined the predictors influencing student progress in the Indonesia Open University. In the second phase, a multiple case study was conducted to investigate in-depth about the extent to which the identified factors (internal, institutional, and external factors) in the quantitative phase have impact on the student progress.

\section{THEORETICAL FRAMEWORK}

This study used three theories of student persistence as a theoretical underpinning: Tinto's model of individual departure, Kember's model of student persistence, and Rovai's composite model of student persistence.

Tinto's model of student departure developed by Vincent Tinto, probably, is the most widely cited theory and the most influential theoretical framework to explain the process of dropout in higher education [9], [18], [19]. The Tinto's model has not only been used to interpret attrition studies in face to face teaching, but has been cited by researchers who conducted studies related to distance education [9], [19]. Tinto's model of student dropout conceptualized persistence as a student's commitment to completing a programme of study at a particular institution. In this model, persistence is an outcome of students' interactions with the institution's academic and social characteristics [7], [20], [21]. Therefore, students who fail to integrate into institution's social and academic system are more likely to drop out of college [7], [21], [22]. Student's ability to interact successfully with institution and other students is the key points for students to persist in their study [23], [24].

Another attempt to explain persistence was made by David Kember [9]. Kember's model of student progress focuses on adult learners and stems from three prominent bases: 1) the seminal work of Tinto about student dropout in the conventional college; 2) Kember's own research on student progress in distance education institutions since the mid-1970s; and 3) a comprehensive review of literature that was employed to examine the connection among variables in the model [25]. In the latest Kember's model of student progress, Kember [9] developed his model of student progress by constructing a model which has two paths: a positive and negative paths. The students who have positive background attributes tend to proceed down the positive path in the model: positive background characteristics (age, sex, years of working experience, marital status, and highest academic qualification) - social integration (enrolment encouragement, study encouragement, and family support) academic integration (deep approach, intrinsic motivation, positive course evaluation, positive telephone counselling, and reading habit) - grade point average (GPA) - cost/benefit analysis - and outcome. In the positive path, the students will be able to integrate study with family, employment, and social life (social integration) and to encompass all facets of a course, the package of learning materials, and all interactions between an institution and the students including both academic and administrative support systems (academic integration). The students who experience a positive path through the study process will be more likely to get satisfactorily grade point average (GPA) score [9], [25], [26]. On the other side, the students with negative entry characteristics tend to have difficulty achieving social and academic integration. The students who move through the study process on the negative path will experience external attribution (insufficient time, event hinder study, distractions, and potential drop-out) and academic incompatibility (surface approach, extrinsic motivation, negative course evaluation, potential drop-out, and English ability) during their study, and finally will be more likely to perform least satisfactorily in their grade point average (GPA) score [9].

Finally, Rovai's composite model of persistence was the influential model to better explain persistence and attrition in online learnings. Basically, Rovai's model is classified persistence factors into two groups: prior to admission and after admission. Prior to admission group contains student characteristics and student skills. Meanwhile after admission group consists of external and internal factors [4].

All of the three models postulate that student persistence in distance education should be explained from at least 3 dimensions: internal factors, institutional factors, and external factors. The extensive literature review also revealed that student persistence is best explained by implementing the student-institution "fit" approach. This approach focuses to illuminate student persistence by exploring internal, institutional, and environmental factors [1], [4], [12], [27].

\section{CONTEXTUAL BACKGROUND}

Indonesia Open University (Universitas Terbuka), established in 1984, is a state university and the only university in Indonesia that teaches entirely by means of distance education. In 2009, Universitas Terbuka enrolled over 600,000 students, residing in different parts of the country and some overseas locations. Over $95 \%$ of these students are working adults. Universitas Terbuka has major roles to play in developing high-caliber human resources needed for the nation's sustainable development. Furthermore, since its foundation, Universitas Terbuka has enrolled over 1.4 million students and has produced over 700,000 alumni, working in various professional fields [28]

Currently, Universitas Terbuka has 4 Faculties (Teacher Training and Educational Science; Mathematics and Natural Science; Economics; Social and Political Science) with 35 Degree Programmes. Besides this, it offers three graduate programmes at the Master's level: Public Administration, Management, and Fisheries Management. Universitas Terbuka media learning resources include 962 printed learning curricula (30\% supplemented with non-printed learning materials), 117 courses with radio tutorials, 419 courses with online tutorials, and 1002 televised tutorial programmes. There has also been increasing usage of 
multi-media learning materials [29].

\section{RESEARCH METHOD}

This study employed a mixed methods research which it focuses on collecting, analysing, and integrating both quantitative and qualitative data in a single study (or series of studies) [30], [31]. The rationale for choosing a mixed methods research is to get complementary in explaining the phenomena of learning situations and students' experience as an adult learner at the Indonesia Open University. Specifically, the research questions of this study which are formulated to explain factors influencing student progress at undergraduate students of Universitas Terbuka, and to what extend the three factors (internal, institutional, and external) influence student progress, are better understood and allowed for a more complete analysis by utilizing and integrating both quantitative and qualitative methods and data.

\section{A. Target Population and Sample}

The target population in this study was undergraduate students who enrolled from the registration periods of 2010.1; 2010.2; and 2011.1 in the Faculty of Social and Political Sciences at the Indonesia Open University. The criteria of selecting the participants consisted of: 1) being undergraduate students of Faculty of Social and political Sciences; 2) students who registered in the admission period of 2010.1 ; 2010.2; and 2011.1; 3) are either admitted as an active or inactive student. Therefore, there were a total of 7686 students who met the criteria.

In the quantitative phase, this study used a convenience sampling due to the limited number of students who reported their email addresses to the Regional Offices. Out of 7686 students who registered in the admission period of 2010.1; 2010.2; and 2011.1, only a total of 3851 students who were recorded as having email addresses in the University database. Considering the low response rate of online survey and estimated responses on average in online survey was about 30 per cent of sampling size [32]-[34], all of 3851 students who had email addresses were invited to participate in the online survey.

In terms of qualitative phase of the study, purposeful sampling was used to purposefully selecting individuals who represented the range of experience on the phenomenon, best answered the research question and who were information rich [35], [36]. In selecting participants, maximal variation sampling was used as a purposeful sampling strategy where the researcher attempted to understand some phenomenon by seeking out persons or settings that represent the greatest differences in that phenomenon [35], [37]. Accordingly, 4 participants from responding students, representing groups of active and inactive students had been selected for case study analysis.

\section{B. Data Collection and Analysis}

\section{1) Quantitative phase}

In the quantitative phase, the study focused on explaining factors that influence student progress. The cross-sectional survey design was employed in this study that data was collected at one point of time [34]. The online survey was undertaken via a virtual platform, iSurvey-Soton (www.isurvey.soton.ac.uk). The survey link was sent to 3851 students by email invitations via survey-Soton website. The link for the survey was uniquely tied to each individual student. Therefore, it is very convenient to send the second and the final third emails to students who do not participate in the first and second survey, accordingly.

The survey instrument used in this study was adapted from previous research with sub-scales demonstrating acceptable validity and reliability.

The first section of the survey explored information related to the academic profiles of students enrolled in Faculty of Social and Political Sciences, the Indonesia Open University. This section focused on course programme, enrolment status of students, reason of non-enrolment, and the main barriers of students.

The next sections were related to the attitudes and perceptions of individuals pertaining to academic motivation, self-efficacy, volitional control, peer interaction, student support services, learning process, cultural orientation, support of family and friends, working environment, and financial problem. The students are asked to respond to items using a five-point Likert scale (Strongly agree; Agree; Neither agree nor disagree; Disagree; Strongly disagree).

Data analysis was divided into two steps. First, this study used descriptive statistics to describe, summarize, and explain students' characteristics. Frequency distribution or one-way tables and cross-tabulation were used to build a basic attribute of each item. Cross-tabulation was used to examine frequencies of observations that belong to specific categories on more than one variable and can be used to identify relationships between the cross-tabulated variables based on the cell values. Cross-tabulation is the easiest way of summarizing data [38]. The results of descriptive statistics were displayed in the form of tables, charts and graphs.In the second step of data analysis, logistic Regression analysis was utilized in determining the significant predictors of student progress.

\section{2) Qualitative phase}

In the qualitative phase, the study attempted to elaborate the results of the quantitative phase obtained in the first phase. The multiple case study design was employed in collecting and analysing the qualitative data.

Purposeful sampling was employed in this multiple case study design with fourparticipants representing two active students and two inactive students. The selection of participants was also based on demographic characteristic, such as age, gender, and ethnicity.

The primary data collection strategy in this qualitative phase was in-depth semi-structured interview. Online interview throughtelephone and email wereselecteddue to participant's requestand long distances among selected participants.

The process of data collection and data analysis are interrelated and often go on simultaneously in the qualitative research. However, the general process of qualitative data analysis consists of three strategies: preparing and organizing the data (text data and image data) for analysis, then reducing the data into themes through the process of coding and condensing the codes, and finally representing the data in Fig. 
1, Table I - Table III, or a discussion [39].

\section{RESEARCH RESULTS}

\section{A. Quantiative Phase}

\section{1) Demographic information}

The most typical age of participants was between 25 and 29 and the majority of them were men. Moreover, their ethnicity was predominantly identified as Javanese; they were mostly graduated from Senior High School; they were employed full-time; and they were primarily married and had children under 18.

The majority of participants undertaken the course programme of English for Translation and then followed by Government Science. They were predominantly registered in the regional office "Jakarta" and were identified as active students. Furthermore, the most cited reason of leaving study for at least one registration period or more was workloads.

\section{2) Descriptive analysis of scale}

The internal factors consisted of 4 variables, including academic motivation, self-efficacy, and volitional control. The items in each scale were measured on a 5-point Likert scale from "Strongly disagree" to "Strongly agree". The results of the research indicated that the majority of participants had high intrinsic and extrinsic motivation. These patterns were also consistent with other two scales that most of the participants from both active group and inactive group had high self-efficacy and volitional control during their studies at the Indonesia Open University.

Institutional factor contained 3 variables: student support services, learning process, and peer interactions. The findings of study revealed that the majority of participants was satisfied with the student support services and learning process at the Indonesia Open University. Furthermore, most of the participants also agreed that peer interaction had significant contribution to support students' learning in the Indonesia Open University.

Meanwhile, external factors consisted of 4 variables: "family and friends", "work environment", "independent cultural orientation", and "interdependent cultural orientation". The majority of participants received full support from family during their studies. However, the majority of inactive students provided "unsure" responses pertinent to support from friends. At the same time, most of participants were encouraged by their employer to pursue a university degree. Nevertheless, most of the inactive students provided "unsure" responses regarding job responsibilities and supports from colleagues. Furthermore, both the active students and the inactive students indicated to have individual and social orientations in theirselves.

\section{3) Logistic regression analysis}

The logistic regression analysis was performed to determine the determinant predictors of student progress by using 12 variables: gender, employment status, intrinsic motivation, extrinsic motivation, self-efficacy, volitional control, student support services, interaction, learning process, work environment, independent orientation, and interdependent orientation.
The results of analysis reported that the Omnibus Tests of Model Coefficients indicated that the Sig. value was .047 ( $P$ <. 05) and this value explained that the model (with 12 predictor variables) had the goodness of fit with the data. The chi-square value in this test was 23.917 with 14 degrees of freedom. The Hosmer and Lemeshow Test also reinforced that the model as being useful. The test showed that the significance value was greater than .05 (.901) which indicated support for the model. For the Hosmer-Lemeshow Test poor fit is indicated by a significance value less than .05 [40].

\begin{tabular}{ccccc}
\multicolumn{5}{c}{ TABLE I: OMNIBUS TEST } \\
\hline \multirow{4}{*}{ Step 1 } & Chi-square & df & Sig. \\
& Step & 23.917 & 14 & .047 \\
& Block & 23.917 & 14 & .047 \\
& Model & 23.917 & 14 & .047 \\
\hline Step & TABLE II: HoSMER AND LEMESHOW TEST \\
\hline 1 & Chi-square & df & Sig. \\
& 3.473 & 8 & .901 \\
\hline
\end{tabular}

Another test offered information about the usefulness of the model. The Cox \& Snell R Square and the Nagelkerke R Square in the table "Model Summary" bestowed an indication of the amount of variation in the dependent variable explained by the model (from 0 to 1 ). In this case, there were two values: .419 and .685. These values designated that the set of predictor variables might explain between 41.9 per cent and 68.5 per cent of the variability in the dependent variable (student progress/non-progress).

TABLE III: MODEL SUMMARY

$\begin{array}{cccc}\text { Step } & -2 \text { Log likelihood } & \text { Cox \& Snell R } & \text { Nagelkerke R } \\ & & \text { Square } & \text { Square }\end{array}$

$17.807^{\mathrm{a}}$

.419

.685

a. Estimation terminated at iteration number 20 because maximum iterations has been reached. Final solution cannot be found

Furthermore, information about the contribution or importance of each predictor variables was provided by the Variables in the Equation table. The Wald test indicated that all variables had Sig. value greater than .05. $(P>.05)$. This finding revealed that there was no the variables that contribute significantly to the predictive ability of the model.

To sum up, the logistic regression analysis produced the model that was useful to explain 41.9 per cent and 68.5 percent of the variability of student progress. This model contained 12 predictor variables.

\section{B. Qualitative Phase}

Cross case analysis from four case studies revealed four central themes related to student progress in the Indonesia Open University: self-motivation, quality of institutional support, interaction, and supporting environment.

Self-motivation in this case included intrinsic and extrinsic motivation. Both motivations had high contribution to student progress. Intrinsic motivation included motivation to pursue new knowledge and extrinsic motivation contained motivation to obtain better career in the future.

High satisfaction of quality of institutional support had been supposed as the important factor in contributing student progress. In this case, satisfaction of institutional support 
consisted of satisfactory experiences about prompt responses provided by faculty staffs to deal with students' complaints, and the delivery of modules. However, there wasan unsatisfactory experience regarding the quality of tutors during online tutorials, such as lack of prompt response from tutors.

Ability to make connections and learning group among peer students has motivated participants in continuing their study and pursuing the undergraduate degree as soon as possible. The connections and learning group were also useful to eliminate lonely feelings during their study.

Supporting environment was also important in influencing the students' decision to be active students. Supporting environment included support and encouragement from external sources such as families and employment.

\section{DISCUSSION}

This study was intended to investigate factors influencing student progress in the Indonesia Open University. In the quantitive phase, logistic regression analysis produced the model contained 12 variables in predicting student progress (gender, employment status, intrinsic motivation, extrinsic motivation, self-efficacy, volitional control, student support services, interaction, learning process, work environment, independent orientation, and interdependent orientation). Meanwhile, the multiple case study analysis found four important factors in contributing student progress: self-motivation, quality of institutional support, interaction, and supporting environment.

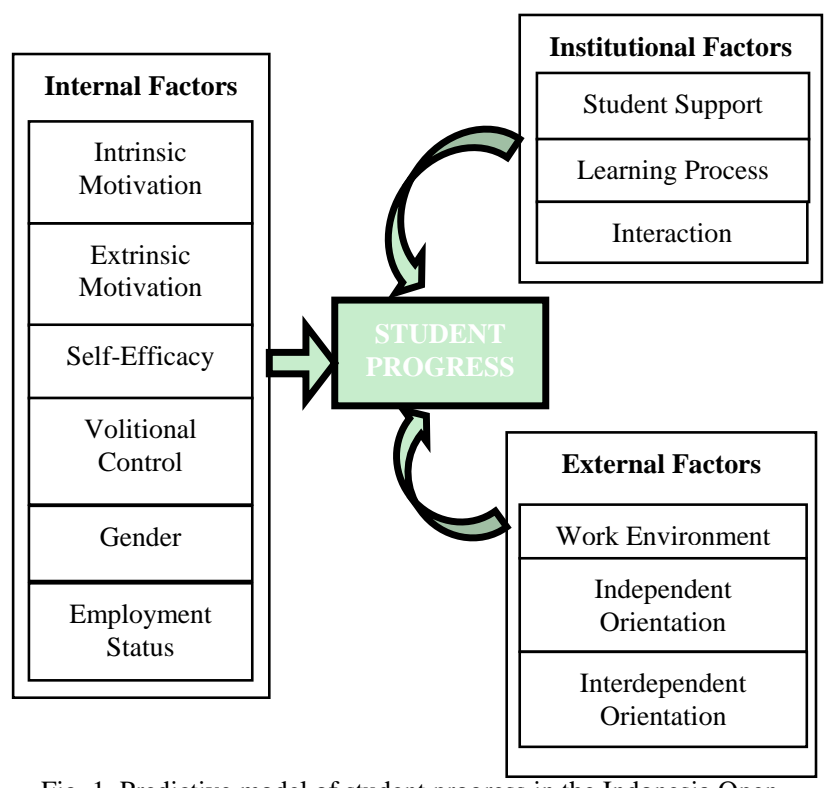

Fig. 1. Predictive model of student progress in the Indonesia Open University.

The quantitative and qualitative findings underlined the importance of 3 dimensions in explaining student progress in the Open University: internal factors, institutional factors, and external factors.

These findings were consistent with the principle ideas of Tinto's model of student departure, Kember's model of student progress, and Rovai's composite model.

The significant contribution of internal factors (self-motivation, self-efficacy, and volitional control), institutional support, and interaction supported Tinto's model of student departure [6], which highlighted the process of dropout as a process of interactions between the individual and the academic and social systems [6], [7].

Meanwhile, the importance of employment status, internal factors, institutional support, interaction, and supporting environment (family and employment) were in line with the concept of social and academic integration from Kembers' model of student progress. Kember [9] defined social integration as the extent to which students are able to integrate study with the employment, social life, and family. Meanwhile, academic integration is defined as embracing all aspects of a distance education course and all elements including both academic and administrative support systems, the learning materials, and all forms of contact between an institution and the students [9], [25], [26]. In addition, in the Kember's model, work circumstances was also vital characteristics that should be taken into consideration along sideindividual attributes, family backgrounds, and educational experiences.

The significant roles of internal, institutional, and external factors in contributing to student progress in the Open University also supported the principle ideas of Rovai's composite model. The importance of internal factors (self-motivation, self-efficacy, and volitional control), institutional factors (learning process, student support services, and interaction), and external factors (family and employment) were consistent with the basic principle of Rovai's model [4] which synthesise the sociological approach of Tinto's model and the psychological approach of Bean and Metzner's model. These findings also reprensented a function of student-institution "fit" approach, in which illuminate persistence and attrition by exploring student, institutional, and environmental variables [4].

Moreover, the fascinating and distinctive finding in the context of the Indonesia Open University is that most participants are extrinsically motivated in pursuing undergraduate degree, particularly motivated for better career in the future. This extrinsix motivation has a major role in motivating students to re-enrol at each semester (an active student). However, the extrinsic motivation does not undermine intrinsic motivation and coexist together in the context of Open University. This finding is supported also by previous research within different context that intrinsic and extrinsic aspects of academic motivation strengthen each other in the non-traditional students in Germany [41].

Based on these findings, two recommendations were proposed in order to enhance student progress in the Indonesia Open University: 1) Develop a need-based support system to provide a well structured support that meet students' needs and challenges; 2) Develop technological tools to facilitate and promote interaction between institution and students. This effort will be enable to maintain and enhance student motivation to continue their studies.

Finally, this study revealed student progress from students' perspective only at one institution, Indonesia Open University.Student progress has usually involved a complex of interplay factors. Future research therefore is needed to explore student progress at various open universities in the world in order to get completeportraitregarding factors 
contributing to student progress and how to motivate students in accomplishing their studies.

\section{REFERENCES}

[1] D. Diaz and R. Cartnal, "Term Length as an indicator of attrition in online learning," Innov. J. Online Educ., vol. 2, no. 5, 2006.

[2] O. Simpson, Student Retention in Online, Open, and Distance Learning, 1st ed., London: Kogan Page, 2003.

[3] S. Carr, "As distance education comes of age, the challenge is keeping the students," Chron. High. Educ., vol. 46, no. 23, p. A39, 2000.

[4] A. P. Rovai, "In search of higher persistence rates in distance education online programs," Internet High. Educ., vol. 6, no. 1, pp. 1-16, 2003.

[5] M. Deimann and T. Bastiaens, "The role of volition in distance education: An exploration of its capacities," Int. Rev. Res. Open Distance Learn, vol. 11, no. 1, 2010.

[6] V. Tinto, "Dropout from Higher Education: A theoretical synthesis of recent research," Review of Educational Research, vol. 45, no. 1. pp. 89-125, 1975.

[7] V. Tinto, Leaving College: Rethinking the Causes and Cures of Student Attrition, 2nd ed., Chicago: University of Chicago Press, 1993.

[8] J. P. Bean and B. S. Metzner, "A conceptual model of nontraditional undergraduate student attrition," Rev. Educ. Res., vol. 55, no. 4, pp. 485-540, 1985.

[9] D. Kember, Open Learning Courses for Adults: A Model of Student Progress, 1st ed., New Jersey: Educational Technology Publications, 1995.

[10] D. Kember, T. Lai, D. Murphy, I. Siaw, and K. S. Yuen, "Student progress in distance education - Identification of explanatory constructs," Br. J. Educ. Psychol., vol. 62, pp. 285-298, 1992.

[11] D. Kember, T. Lai, D. Mlurphy, I. Siaw, and K. S. Yuen, "Student progress in distance education courses: a replication study," Adult Educ $Q .$, vol. 45 , no. 1, pp. 286-301, 1994.

[12] Y. Lee and J. Choi, "A review of online course dropout research: implications for practice and future research," Etr\&D-Educational Technol. Res. Dev., vol. 59, no. 5, pp. 593-618, 2011.

[13] G. Moore and G. Kearsley, Distance Education: A System View of Online Learning, 3rd ed., Belmont, USA: Wadsworth, 2012.

[14] T. Belawati, "Open and distance learning: Conceptual origins," in Policy and practice in Asian Distance Education, T. Belawati and J. Baggaley, Eds., Ottawa, 2010.

[15] J. S. Daniel, Mega-Universities \& Knowledge Media: Technology Strategies for Higher Education, Oxon: Routledge, 1999.

[16] M. G. Moore and G. Kearsley, Distance Education: A Systems View of Online Learning, 3th ed., Belmont, CA: Cengage Learning, 2012, pp. 242-267.

[17] H. Choi, Y. Lee, I. Jung, and C. Latchem, "The extent of and reasons for non re-enrollment: A case of Korea National Open University," Int. Rev. Res. Open Distance Learn, vol. 14, no. 4, 2013.

[18] D. A. Guifrida, "Toward a cultural advancement of tinto's theory," Rev. High. Educ., vol. 29, no. 4, pp. 451-472, 2006.

[19] D. Kember, "A longitudinal-process model of drop-out from distance education," J. Higher Educ., vol. 60, no. 3, pp. 278-301, 1989.

[20] A. F. Cabrera, "The convergence between two theories of college persistence," ASHE Annual Meeting Paper, 1990.

[21] V. Tinto, "Stages of student departure: reflections on the longitudinal character of student leaving," J. Higher Educ., vol. 59, no. 4, pp. 438-455, 1988.
[22] J. R. Hammond, Predictors of Persistence in Distance Education, University of Louisville, Kentucky, USA, 2006.

[23] A. H. Lint, "The impact of student progress factors on student persistence in e-learning," Trident University International, California, US, 2011.

[24] S. Porta-Merida, "Online learning success: Underlying construct affecting student attrition," Lynn University, United States of America, 2009.

[25] A. Woodley, P. de Lange, and G. Tanewski, "Student progress in distance education: Kember's model revisited," Open Learn. J. Open, Distance e-Learning, vol. 16, no. 2, pp. 113-131, 2001.

[26] N. V. Ivankova and S. L. Stick, "Students' persistence in a distributed doctoral program in educational leadership in higher education: a mixed methods study," Res. High. Educ., vol. 48, no. 1, pp. 93-135, 2007.

[27] H. Street, "Factors influencing a learner's decision to drop-out or persist in higher education distance learning," Online J. Distance Learn. Adm., vol. 13, no. 4, p. 5, 2010.

[28] U. Terbuka. UT dalam angka pada 30 April 2012. Universitas Terbuka. [Online]. Available: http://www.ut.ac.id/tentang-ut/ut-dalam-angka.html\#kepulauan, 2012.

[29] U. Terbuka, “UT Catalogue," Jakarta, 2012.

[30] J. W. Creswell and V. L. P. Clark, Designing and Conducting Mixed Methods Research, California: Sage Publications, 2011.

[31] S. N. Hesse-Biber, Mixed Methods Research: Merging Theory with Practice, New York: The Guilford Press, 2010.

[32] V. M. Sue and L. A. Ritter, Conducting Online Surveys, London: Sage Publications, 2007.

[33] D. A. Dillman, Mail and Internet Surveys: The Tailored Design Method, 2th ed., New Jersey: John Wiley \& Sons, 2007.

[34] D. A. de Vaus, Surveys in Social Research, 5th ed., Crows Nest, NSW: Allen \& Unwin, 2002.

[35] J. W. Creswell, Educational Research: Planning, Conducting, and Evaluating Quantitative and Qualitative Research, 4th ed., Boston: Pearson, 2012.

[36] P. Maykut and R. Morehouse, Beginning Qualitative Research: A Philosophic and Practical Guide, London: The Falmer Press, 1994.

[37] J. A. Hatch, Doing Qualitative Research in Education Settings, New York: State University of New York Press, 2002.

[38] K. Singh, Quantitative Social Research Methods, London: Sage Publications Ltd, 2007.

[39] J. W. Creswell, Qualitative Inquiry and Reseach Design: Choosing among Five Approaches, California: Sage Publications, 2007.

[40] J. Pallant, SPSS Survival Manual: A Step by Step Guide to Data Analysis Using SPSS for Windows (Version 12), Sydney: Allen \& Unwin, 2005.

[41] U. Wilkesman, H. Fischer, and A. Virgillito, "Academic motivation of students: The German case,” Dortmund, Germany, 2012.

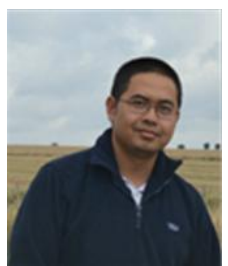

Muhammad Husni Arifin was born on August $28^{\text {th }}$, 1977. He received his master degree in sociology from University of Indonesia in 2004. From 2005, he worked as a full time lecturer and researcher at the Indonesia Open University (Universitas Terbuka), Indonesia and he is interested in distance education, sociology of education, and higher education. Now, he is undertaking a $\mathrm{PhD}$ programme in education at the University of Southampton, United Kingdom. 